\title{
Dying from asthma
}

I: has comc as a surprise that the most common topic in papers so far submilled to the thunch concerms the high rate of mortality from asthma in young people. This brought the realization that I probably know less than I ought about the factors thought to contribute to asthma mortality, and sent ne alt on a self-directed learning exercise, in truc McMaster tradition. Also in this tradilion, I sought Iclp from MEDLINE and from colleagues that know a lot more than I do. A search of the last lwo years publicaltoms. Im imed to reviews in English, lumed up 33 papers. which I will not be referencing becaltic they atre just as casy for you to retrieve as me to list them; however, I will be telighted to send them (1) anyonc who wants them. As to colleagues, I have the good fortune to have Malcolm Scirs close by, and lic policly and modestly sent me a reprint of a paper written in cullaboration with a New Faland colleateruc. This I found to be a superb review and I will give the reference as you may not conte atross is ( 1 ). From these sources, somc thoughts from a noncexpert.

First, many papers refer to asthma deaths of epidemic proportions. Sears provides the data to put this statement into perspective. In the 1960 s deaths from asthma in the five- to 34-year age bracket increased in New Zealand, Australia and the United Kingdom from around onc 10 between two and three per 100,000 persons in this age group, falling to one to two by 1974 ; in the period 1977 to 1988 New Zealand experienced a secont increase that peaked in 1981 when it reached 4.1 per 100,000 , "a figure not matched elsewhere in the world either belore or since". Meinwhile, the rate in Canada was between 0.2 and 0.3 in the ' 60 s and '70s and has since crept up to reach 0.51 in $[9$ so,

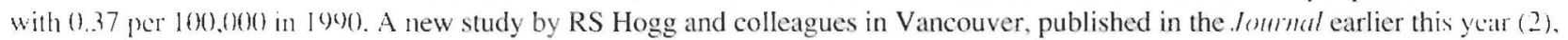
exammed changes in mortality rales and calculated their impact on life expectancy. They found a gradual reduction in rates, greater for males than lemales, frum a high of $4.5 \mathrm{~m}$ the carly $1950 \mathrm{~s}$ (0) atround 2.0 per 100,000 in the 1980 s; in the age group five to 34 years the rates were approximately l/10h of those in New / saland, att (1.20) 100.45 , with no significant trend over the 45 years under study. Hogg et al concluded thit asthma did not have a significant impact on the overall life expectancy of Canadians. The 'epidemics' of increased mortality rates followed the markcting ol polent betaz-agonists and declines in mortality followed reductions in their use; Sears and Taylor provide the evidence in their revicw, and have been in the forefront of research on which this conclusion may be based. Bearing in mind the recent report of the World Health () gamization that poverty is the matin cause of illness and death in developing countries, the absence of statistics from poorer countries is probably of great importance; the data reviewed by Sears and Taylor were obtained in six of the G-7 countries and in five others that probably teel that they also should be in this economic grouping. None of them will be wilhin an order ol magnitude of the countries that spend as little as $\$ 4$ for each of their subjects per year on health care.

Second, several of the reviews provide evidence from the United States that show higher mortality in Blitcks than in Caucasianns, and within cities such as New York and Chicago higher rates in the poorer areas. Also in those areas, males oulnumbered lemlialcx by three to one: drug abuse was not a factor. Clearly psychosocial and economic factors that may influence access to carte and effective treatment are of great importance. In a study of patients dying in Brooklyn. only fwo of 14 patients were receiving steroids.

Third, it number of studies have tried we explain why individual patients died from asthma. All considered most of the deaths as preventable and provided evidence that the following factors were important: poor perception of asthna severity: inadeyuate education regarding the illness and poor compliance with treatment; delay in secking treitment: and significant iatrogenic factors resulting in an inadequate and slow treatment response.

Where does this leave us, as Canadian respirologists? We cin feel happy that our mottality rates alte not bettered, but we cannol be conplatemt. The effect of the socioeconomic factors are worrying. expecially at a time when there is a risk that health services atre going to get less accessible; we must ensure that they do not interfere with access to optimal management. The importance of pattient educiation and particularly of specific self-management instructions and goals of treatment was emphasized in the recent first supplenent to the fournet (19)5:2|Suppl A]:1A-52A). Finally, education for physicians must be a priority; at recent review of the results of practice audits suggested that mitny physicians are unaware of the guidelines for optimal management of severe asthmit.

Norman L. fomes $M D$

Editor-in-Chief

Cantalian Respiratory Journal

\section{REFERENCES}

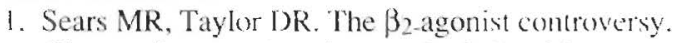
Observations, explanations and relationship) to asthma cpidemiology. Drug Safety [0(9):11:259-83.
2. Hogg RS. Schechter MT, Montaner JSG, Hogg JC. Asthma mortitity in Canada, 1946 to 1990. Can Respir J $1995: 2: 01-6$. 


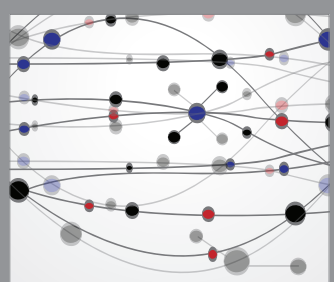

The Scientific World Journal
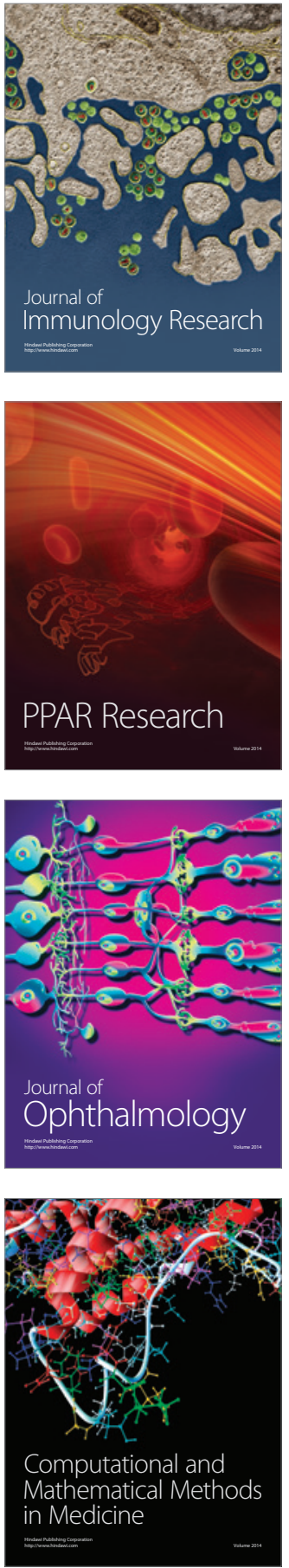

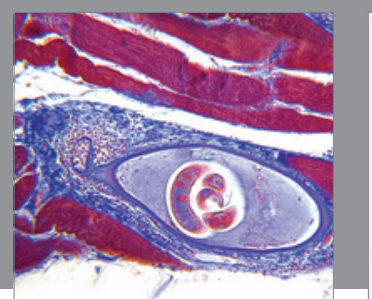

Gastroenterology Research and Practice

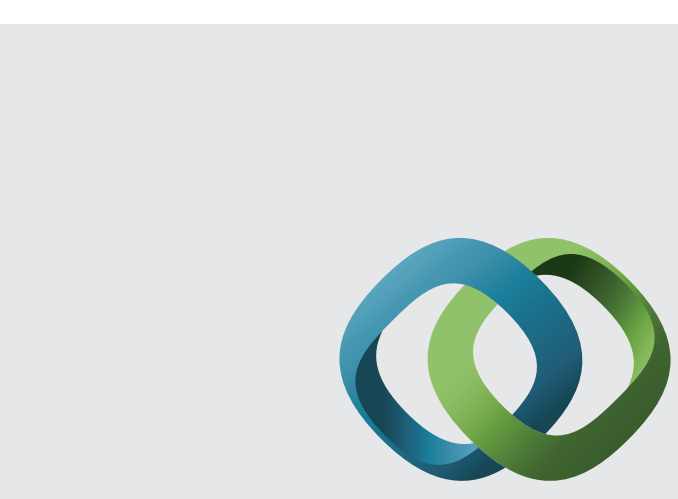

\section{Hindawi}

Submit your manuscripts at

http://www.hindawi.com
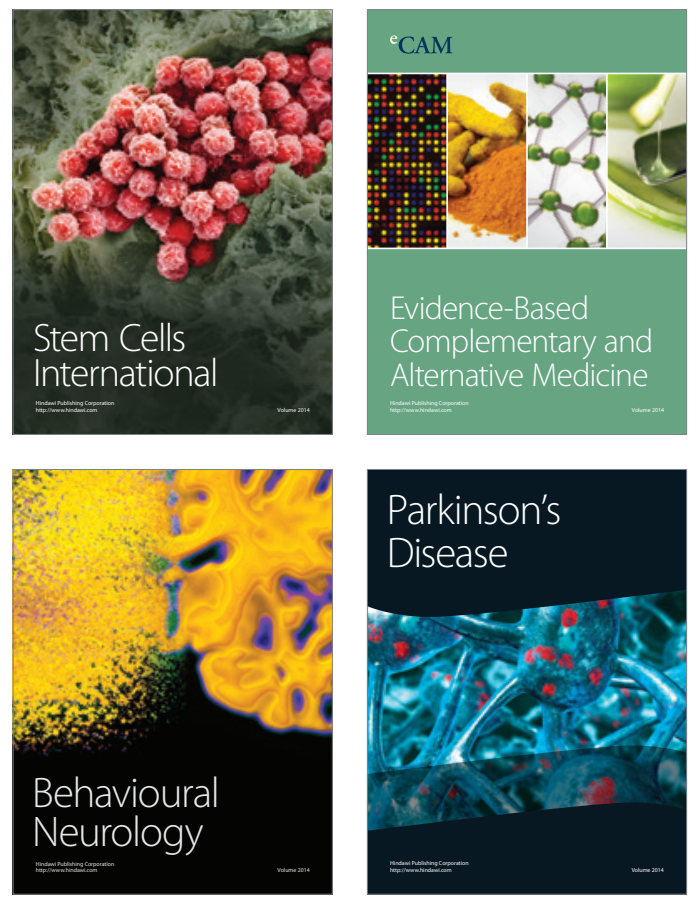
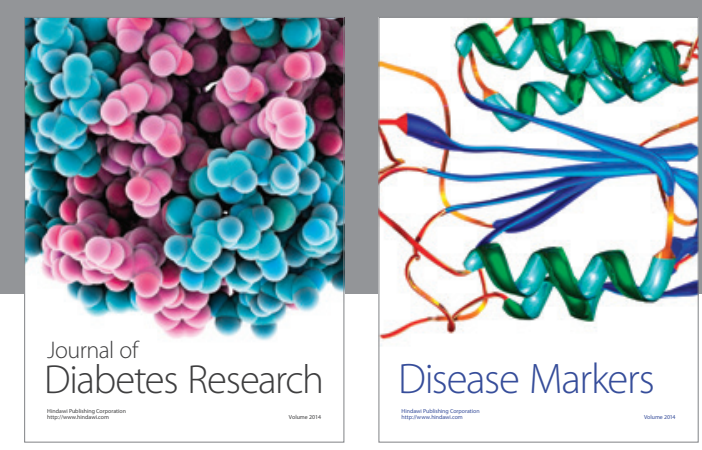

Disease Markers
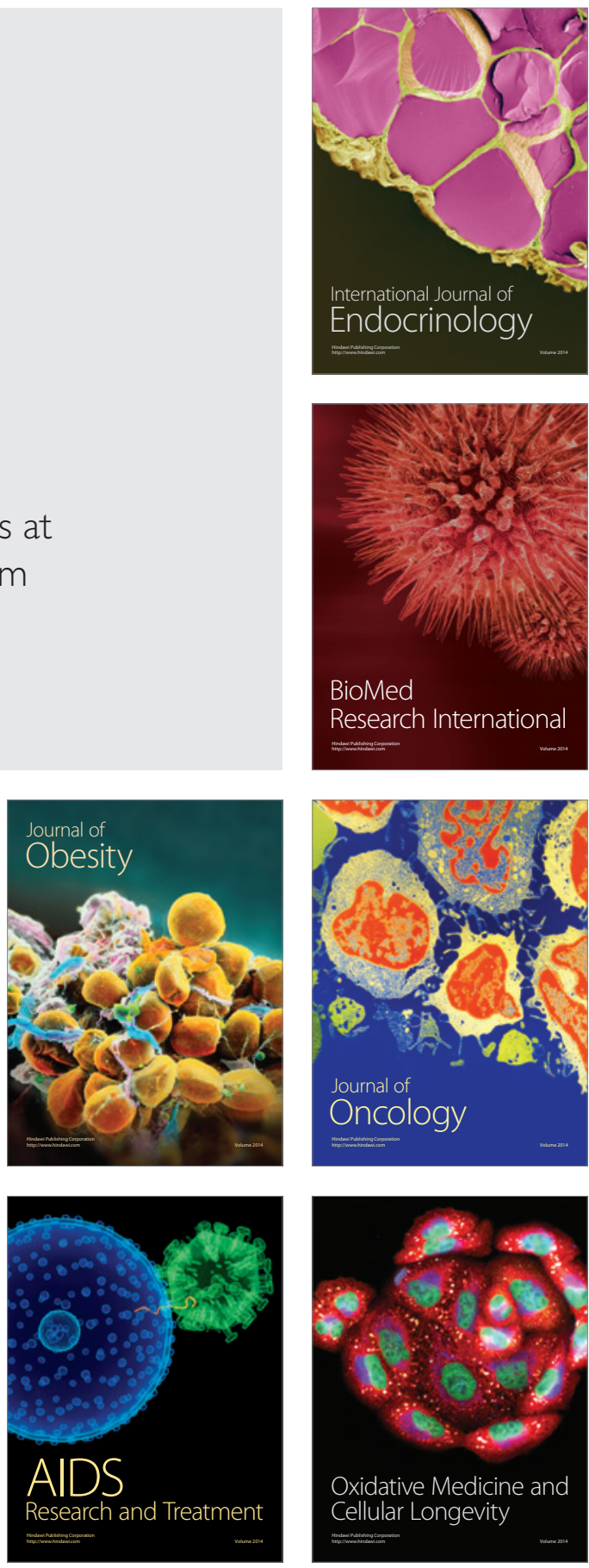